\title{
SARESP E DEFICIÊNCIA INTELECTUAL: SENTIDOS PARA JustiFICAR, TÁtICAS PARA DRIBLAR BAIXOS ÍNDICES
}

\author{
DANIELLE CRISTINA NOgUEIRA ${ }^{1}$
}

ADRIANA VARANI ${ }^{2}$

\begin{abstract}
RESUMO: Este artigo pretende refletir sobre os sentidos produzidos pelos professores da Rede Pública Estadual de São Paulo e suas táticas para lidar com a avaliação externa - SARESP e produção do fracasso escolar via diagnósticos de Deficiência Intelectual. Como suporte teórico foram estudados alguns autores da temática avaliação como Freitas e Luckesi, da perspectiva histórico-cultural na compreensão da Deficiência Intelectual e Certeau com o conceito de táticas. Os dados foram produzidos por meio de entrevistas semiestruturadas com os professores, levando-nos à compreensão da deficiência intelectual e como produzir, a partir dela, uma escola meritocrática. Foi possível concluir que, em razão das relações estabelecidas entre políticas de governo e escola, os professores olham para a deficiência intelectual como um elemento a mais a ser superado em nome de um índice, e a necessidade de enxergá-la em sua concretude histórica e contextualizada de produção de fracasso escolar.
\end{abstract}

Palavras-chave: SARESP. Deficiência Intelectual. Táticas.

\section{SARESP AND INTELLECTUAL DISABILITIES: SENSES TO JUSTIFY, TACTICS FOR DODGE LOW INDICES}

ABSTRACT: This article objective to reflect on the meanings produced by the teachers of the State Public Network of São Paulo and their tactics to get along with the external assessment - SARESP and production of school failure via Intellectual Disability diagnostics. As theoretical support was studied some authors of the thematic assessment as Freitas e Luckesi, of cultural-historical perspective in the understanding of Intellectual Disability and Certeau with the concept of tactics. The data were produced through semi-structured interviews with school teachers taking in the understanding of intellectual disability and how to produce from it, a meritocratic school. It was concluded that, because of the relations between government and school policies, teachers look for intellectual disability as one more element to be overcome in the name of an index, and the need to see it in its historical concreteness and contextualized of school failure production.

Keywords: SARESP. Intellectual Disabilities. Tactics.

\footnotetext{
${ }^{1}$ Mestre em Educação pela Universidade Federal de São Carlos - UFSCar. Professora Coordenadora do Núcleo Pedagógico da Diretoria de Ensino de Votorantim/SP.

${ }^{2}$ Doutora em Educação pela Universidade Estadual de Campinas. Professora Doutora I da Universidade Estadual de Campinas.
} 


\section{SARESP Y DISCAPACIDADES INTELECTUALES: INSTRUCCIONES PARA JUSTIFICAR, TÁCTICAS PARA SE ESQUIVAR DE BAJOS ÍNDICES}

RESUMEN: Este artículo reflexiona sobre los significados producidos por los profesores de la Red Pública del Estado de São Paulo y sus tácticas para hacer frente a la evaluación externa - SARESP y la producción de fracaso escolar a través del diagnóstico de discapacidad intelectual. Como soporte teórico se estudiaron algunos autores de la temática evaluación como Freitas y Luckesi, de la perspectiva histórico-cultural en la comprensión de la discapacidad intelectual y de Certeau con el concepto de tácticas. Los datos fueron producidos a través de entrevistas semiestructuradas con profesores, llevándonos a la comprensión de la discapacidad intelectual y como producir, a partir de ella, una escuela de meritocracia. Se concluyó que, debido a los vínculos entre las políticas del gobierno y de la escuela, los maestros miran para la discapacidad intelectual como un elemento más que hay que superar en nombre de un índice, y la necesidad de mirarla en su concreción histórica y contextualizada de producción de fracaso escolar.

Palabras clave: SARESP. Discapacidad intelectual. Táctica.

\section{Primeiras palavras de contextos}

A história que abre o caminho trilhado nesta pesquisa é a narrativa de uma educadora que, ao iniciar seu ofício, se depara com a realidade de uma escola muito carente. Essa escola contava com aproximadamente 242 alunos no ano de 2011, destes 20 com laudos como Deficiência Intelectual (DI). A esses alunos também era recaída a responsabilização pelo baixo resultado da escola na avaliação externa Sistema de Avaliação do Rendimento Escolar do Estado de São Paulo (SARESP).

Diante disso, interessava-nos, a priori, compreender como se davam esses diagnósticos de Deficiência Intelectual na escola pesquisada e se tal ação impactava no resultado do Índice de Desenvolvimento da Educação do Estado de São Paulo (IDESP). Porém, ao longo de um ano e meio de pesquisas, sentimos que era necessário alterar tal objetivo por uma questão estrutural, uma vez que a pesquisa demandava tempo maior do que teríamos para desenvolver uma temática tão complexa.

Em face disso, passamos a nos orientar por outro dado que nos chamou a atenção na pesquisa: os sentidos atribuídos por professores para a avaliação externa, no interior de uma 
Escola Prioritária ${ }^{3}$, em que as metas previstas pela Secretaria de Educação de São Paulo não eram atingidas. Alterado o objetivo, a Deficiência Intelectual passou a se constituir apenas um dos indicadores de análise quando os professores nos apresentavam os sentidos produzidos. $\mathrm{E}$ é sobre esse indicador que vamos desenvolver este texto.

Da reflexão produzida a partir da pesquisa, o estudo dos sentidos era a preocupação inicial, e com a produção dos dados pudemos perceber que os sujeitos no cotidiano escolar construíam táticas para lidar com as consequências da avaliação externa. As táticas constituíam um conjunto de ações do movimento da escola em relação ao que lhes era imposto.

Para desenvolver a pesquisa, lançamos mão de um estudo de caso da Escola Prioritária a que denominamos de Escola do Meio ${ }^{4}$, utilizando-nos de vários instrumentos. Neste texto nos pautaremos nos discursos construídos pelos professores nas entrevistas semiestruturadas para refletir sobre os sentidos para a relação avaliação e DI e as táticas do cotidiano produzidas para lidar com esta relação.

Em se tratando de SARESP e DI, a suposta relação entre ambos já aparecera antes mesmo de a pesquisa de campo ser iniciada, em 2011, quando a autora que esteve em campo começou o trabalho na "Escola do Meio", deparando-se com uma quantidade inesperada de alunos com diagnósticos de DI. Era uma sala de sétima série, com 36 alunos, destes, oito deles constavam na lista de chamada como DI e ainda havia aqueles que, segundo a coordenação da escola, eram DI, mas não tinham laudo ainda.

Dessa preocupação, surgiram algumas indagações por parte dos professores sobre a condição dos alunos que eram tidos como DI. A grande dúvida que permeava as reuniões de Aula de Trabalho Pedagógico Coletivo (ATPC) era sobre como tais alunos fariam essa avaliação no final do ano. Essa história rendeu grandes discussões sobre se os alunos considerados DI "contavam ou não" no resultado do IDESP.

\footnotetext{
${ }^{3}$ Escolas prioritárias são as que não obtiveram um bom desempenho na avaliação SARESP. Para tal definição a Secretaria considera, em cada escola, o percentual de alunos que tiveram o desempenho "abaixo do básico" em uma das áreas: Português e Matemática. Essa medida, segundo uma nota no site Observatório da Educação sobre o programa Educação- Compromisso de São Paulo é para reduzir as desigualdades de aprendizado no Estado. De acordo com esse programa, isso será efetivado por meio da intervenção, acompanhamento e monitoramento pelas coordenadorias.

${ }^{4}$ Por uma questão ética, o nome da escola, bem como dos entrevistados foram alterados. Nesse campo da ética em pesquisa também foi construído um termo de Consentimento Livre e Esclarecido que os professores assinaram como forma de concordância e esclarecimento sobre a pesquisa realizada.
} 
Dessas questões havia duas probabilidades, ou o aluno diagnosticado como DI constava no resultado do IDESP e assim a escola teria uma chance a menos de alcançar os índices, uma vez que muitos desses alunos mal dominavam a leitura e escrita, ou então eles não contabilizavam no resultado. Fator esse que explicaria o fato de haver tantos alunos diagnosticados como DI quando, na verdade, eram casos de defasagem de aprendizagem, mas isto não apareceria no resultado porque eles não apareceriam, já que o resultado das avaliações deles não comporia a média final.

Após quase dois anos de estudo e de muitos discursos não oficiais pronunciados até por Supervisores de Ensino de que o aluno com diagnóstico de DI constaria no IDESP, chegamos à resposta oficial da Secretaria Estadual da Educação (SEE), via e-mail, de que todos os alunos cadastrados na Companhia de Processamento de Dados do Estado de São Paulo (Prodesp) como DI não seriam computados no cálculo do IDESP, exceto para cálculo do fluxo: evasão ou repetência. Seria então mais uma tática da escola colocar alunos com dificuldade de aprendizagem como DI para driblar os baixos índices?

Nessa condução da pergunta vamos refletir sobre os sentidos produzidos pelos professores para a relação entre SARESP e DI ou, mais especificamente, SARESP e fracasso escolar. E a discussão será sobre como eram utilizados os dados do DI nas avaliações em larga escola, em especial, na dimensão das táticas construídas.

Contudo, para compreender tal relação, a produção de sentidos dos profissionais, precisamos antes entender a produção do Deficiente Intelectual no interior da escola. Para tanto, pensamos ser necessário identificar qual era o discurso da Secretaria Estadual de Educação de São Paulo sobre DI, para depois identificarmos qual postura assumiríamos na pesquisa, haja vista que o próprio termo tem diferentes conceitos, o que depende do referencial teórico utilizado. E, por fim, identificar o olhar para os sentidos dos professores para essa relação.

\section{As perspectivas de DI em jogo}

Inicialmente, para a compreensão de tal fator a partir do que a Secretaria Estadual de São Paulo entende por Deficiência Intelectual, utilizamos o livro Deficiência Intelectual: realidade e ação, 2012, uma publicação da Secretaria da Educação do Estado de São Paulo, organizada pela Professora Doutora Maria Amélia Almeida, docente no PPGEE/UFSCar. Nesse material 
encontramos a contextualização histórica sobre a Deficiência no Brasil e no Estado de São Paulo, com enfoque para o fato de que a rede estadual paulista é pioneira na oferta de atendimento educacional especializado a alunos com necessidades educacionais especiais.

Após contextualizar o campo da produção da educação especial, as autoras, ao se pautarem na alteração de "retardo mental" para "deficiência intelectual", tomam a definição de DI a partir do que se firma na Declaração de Montreal, em 2004, na qual se declara que:

\begin{abstract}
A deficiência intelectual, assim como outras características humanas, constitui parte integral da experiência e da diversidade humana. A deficiência intelectual é entendida de maneira diferenciada pelas diversas culturas o que faz com que a comunidade internacional deva reconhecer seus valores universais de dignidade, autodeterminação, igualdade e justiça para todos (Montreal, 06 de outubro de 2004 apud SÃO PAULO, 2012, p. 54).
\end{abstract}

Em outro capítulo desse material e especificando melhor o conceito, assume-se uma conceituação da Organização Mundial da Saúde (OMS) sobre a Deficiência Intelectual em uma abordagem positivista.

\begin{abstract}
A Deficiência Intelectual é considerada um prejuízo na funcionalidade caracterizada por importantes limitações, tanto no funcionamento intelectual quanto no comportamento adaptativo (conceitual social e prático). Uma deficiência é a expressão das limitações no funcionamento individual dentro de um contexto social e representa uma desvantagem substancial para o indivíduo, como está apresentado pela CIF- Classificação Internacional das Deficiências, Incapacidades e Limitações, adequada ao modelo social, pois sua proposta de conceituação das deficiências e incapacidades vai além da doença, tem um enfoque mais social do que médico e, por isso mais inclusivo (OMS, 2001, CARVALHO, 2008 apud SÃO PAULO, 2012, p. 65).
\end{abstract}

Dado o conceito de DI adotado pela Secretaria, uma abordagem médica em que a deficiência se encontra no aluno, as autoras destacam a necessidade de o profissional que avalia ter uma visão consciente na escolha do instrumento de testagem e, posteriormente, para a interpretação. Segundo Gonçalves e Machado (2002, p. 65), "o continente em que o indivíduo se encontra inserido revela dados significativos e seletivos na sua organização". Diante disso, a Secretaria reforça que cabe a ele (o profissional que avalia) observar o histórico pessoal do aluno, evitando conduzir a investigação para considerações que evidenciem resultados incorretos, diante da limitação de seu desempenho. 
O material traz também como objetivo descrever as causas e situações que levam à deficiência intelectual resultante de algumas síndromes e busca também proporcionar ao profissional da educação o entendimento das variadas dificuldades escolares observadas na população de alunos acometidos pelas síndromes descritas. Das situações apresentadas, as autoras descrevem os fatores de risco e causas da DI em períodos pré-natais em que há incidência de $55 \%$ a $75 \%$, nos perinatais em que a incidência é de $10 \%$ e o pós-natais, em que a incidência é de $5 \%$. Diante disso, as autoras destacam quatro fatores de risco nesses três períodos, sendo: biomédicos, sociais, comportamentais e educacionais.

É importante ressaltar que, dos fatores de risco apresentados, apenas um é apresentado nesse material como fator biológico, os outros três fatores estão relacionados ao modo de vida da família da criança como a pobreza, o uso de drogas e mesmo a falta de encaminhamento para intervenção após a alta hospitalar da mãe. O discurso adotado no material é o mesmo do Banco Mundial, em que a pobreza é a causa da Deficiência Intelectual e que esta deficiência só pode continuar gerando mais pobreza. Assim, as autoras alertam sobre a avaliação dos alunos com suspeita de deficiência intelectual, pois os testes neuropsicológicos, embora sejam fundamentais, e a interpretação dos resultados devem levar em conta o contexto étnico e cultural, o nível educacional, a motivação, a cooperação e as deficiências associadas ao paciente.

A proposta de estudo oferecida pela SEE para os professores da rede estadual, concretizada nessa publicação, está inclinada para a abordagem positivista, uma vez que está explícita na sua composição a abordagem médica da deficiência em que a incapacidade e as limitações se encontram no indivíduo e que as causas sociais da DI se concretizam na pobreza gerando cada vez mais pobreza. Entretanto, o material traz um modelo de avaliação pedagógica para inserção de alunos nas salas de AEE baseada na abordagem sociointeracionista de Vygotsky (2002), que enfatiza a relação professor-aluno-contexto, valorizando o aspecto sociocultural no desenvolvimento cognitivo do indivíduo, sendo esta a única referência à abordagem histórico-cultural (SÃO PAULO, 2012, p. 92).

Contudo vimos estudando outra perspectiva, a histórico-cultural, que acaba, em princípio, se contrapondo à perspectiva assumida pela Secretaria de Educação do Estado de São Paulo. Nesse enfoque teremos prioritariamente os estudos de Vygotsky e seus colaboradores, contribuindo para uma valorização das interações sociais nos processos de desenvolvimento 
humano. Para Vygotsky e seus colaboradores seria impossível separar o sujeito biológico do social, já que o sujeito singular só se singulariza na e pela cultura, ou seja, seu desenvolvimento depende de outros membros de sua cultura.

Vygotsky (2002) chama a atenção para o modo com os quais as crianças com deficiências são educadas, afirmando que esta não deve ser minimalista, nem reducionista, uma vez que tais teorias minimalistas e reducionistas tentam na prática reduzir a educação da criança com atraso como em um adestramento em que se passa a tratar o processo de formação do homem ao adestramento de um semi-animal. Trata-se de um método em que a obediência é fundamental, nele o indivíduo cumpre automaticamente a hábitos úteis que são considerados ideais para sua educação.

A justificativa de Vygotsky (2002) é que o processo de ensino-aprendizagem se dá desde a infância, que o ser humano nasce apenas possuindo os recursos biológicos e é a partir do meio social que ele concretiza seu processo de humanização. Para Góes (2004) ocorre que muitos sujeitos com deficiência não agem de forma autônoma em relações pessoais e atividades, pois continuamente agem a partir da tutela, do cuidado, da superproteção, da subestimação e da infantilização. Em outras palavras, o que ocorre em nossa sociedade é uma cristalização da imagem infantilizada do indivíduo com deficiência.

Desse modo, o material de apoio oferecido aos professores da rede nos dá a compreensão de uma aprendizagem medicalizada, inclusive quando busca orientar os professores quanto ao entendimento da deficiência intelectual alertando que a maioria das causas da DI não tem cura, porém que é necessário realizar um diagnóstico preciso (como se fosse possível) para o aconselhamento genético do paciente e de sua família.

Em consonância com essa fala está a Nota Técnica no 04/2014 SECADI/MEC, em que não é necessária a apresentação de documentos clínicos comprobatórios (laudo médico/diagnóstico clínico) para informar a matrícula de alunos com deficiência, somente a avaliação pedagógica. Caso seja necessário, o professor de AEE pode se articular com profissionais da área da saúde, tornando o laudo médico um documento anexo ao Plano de AEE, sendo este apenas complementar.

Tendo a avaliação do professor como o primeiro diagnóstico para a verificação do aluno DI, ocorre um duplo equívoco, uma vez que as categorias de análise são superficiais e 
restritas somente a um padrão considerado ideal para um aluno "normal" como a apropriação da linguagem e escrita de acordo com uma faixa etária. Moysés (2001) a caracteriza como "medicalização da aprendizagem", que resulta, então, do processo de biologização da educação e do fracasso escolar. Essa biologização pode ser caracterizada por uma isenção da culpa pelo não aprendizado do aluno em sala regular e de tal modo como uma divisão de tarefas entre o professor de sala regular e o de sala de recurso, pois o único a carregar a culpa por não aprender é o próprio aluno.

Sobre o diagnóstico inicial do aluno descrito como D.I, transcrevo um trecho de uma entrevista com a professora da sala de recurso da escola pesquisada em que ela explica como se dá o encaminhamento deste para a sala de recurso e seu cadastramento na Companhia de Processamento de Dados do Estado de São Paulo (PRODESP).

O encaminhamento é feito por vocês, vocês são os principais, o ponto $x$ da questão, por isso que eu sempre falo, nosso tempo é curto pra trabalhar com vocês né? [...] porque vocês que vão em sala de aula detectar a dificuldade daquele aluno, você na sua área ou até mesmo em, de repente você vê que ele não realiza cálculo. Então vocês vão estar contando como vocês sempre fazem. Vocês têm o Anexo I e vocês sempre vão estar preenchendo, às vezes coletivamente, então vocês vão fazer um relatório, não é nem um relatório, vão colocar o ponto crítico da criança lá: não presta atenção, fica afastado do grupo, não interage ou o aluno é agressivo, tanto com o professor às vezes com o aluno. Essa agressividade tanto pode ser verbal ou até mesmo física (EN - Rita)

Essa verificação inicial proposta para os professores da sala de aula regular pode apresentar déficits justamente porque está carregada de juízo de valor, principalmente ao relacionar comportamento à deficiência e a desvincular a relação social a ela. Mesmo que haja uma intencionalidade positiva nessa ação, a tentativa simplória de justificar uma dificuldade por meio de uma "patologização" dos sintomas corrobora para a exclusão de tais alunos (MOYSÉS, 2001). Esta autora chama a atenção para a condição que esses alunos podem vivenciar, visto que, ao esperar menos dos alunos considerados como sendo aqueles com distúrbios, o professor acabará por investir menos em sua aprendizagem. A repercussão poderá se dar também no comprometimento de aspectos relativos às relações de ensino e de aprendizagem em sala de aula, e na autoestima dessas crianças, que passam a se considerar incapacitadas para a construção efetiva de práticas de leitura e de escrita e a incorporar tal incapacidade como característica 
própria e pessoal. A autora ressalta ainda que, em decorrência do comprometimento desses aspectos, tais crianças sofrem daquilo que ela denominou como "institucionalização invisível", uma vez que elas permanecem no espaço físico da sala de aula, mas são excluídas do processo de ensino-aprendizagem.

Para que a avaliação pedagógica não se limite a um juízo de valor do professor para com o aluno faz-se necessário repensar a todo o momento a ação-reflexão-ação de nossa prática enquanto professores, repensar os processos avaliativos utilizados para a verificação do aluno com suspeita de DI. Porém, tal processo não ocorre do dia para a noite, precisamos estar em formação contínua para tal mudança.

\section{Sentidos produzidos pelos profissionais}

A falta de explicação para a pergunta: por que esses alunos não estão aprendendo nessa escola? Levar-nos-ia a outros mecanismos de busca por respostas em que talvez a pergunta devesse ser reformulada para o que os alunos não estão aprendendo na escola? Haja vista que é inegável que a escola é um lugar em que se aprendem diversas coisas. Ao adentrar na escola a criança nunca mais será a mesma, independente da quantidade de conteúdos vistos por ela ou não.

O fato é que o discurso de que os alunos não estão aprendendo na escola é ecoado pelos professores a cada resultado das avaliações externas e isto de tal forma os lança para o abismo dos professores que fracassam. Nesse abismo, por pior que pareça ainda, sobra lugar para mais uns e outros, pois o fracasso ainda é tido como uma incapacidade pessoal seja ela do professor que não conseguiu ensinar ou então do aluno que não conseguiu aprender. Em pelo menos um dos casos existe o purgatório, lugar em que os alunos podem ir para se redimir de seus pecados, digo erros! A este lugar chamamos de Sala de Reforço ou de Recurso e elas estão cheias de crianças configurando aquilo que Bourdieu e Champagne (2001) chamaram de "exclusão branda", onde os que não se adaptam se apartam.

Pelas entrevistas realizadas, podemos encontrar vestígios dessa exclusão branda que tem como precursor a desigualdade social que não possibilita a todos os alunos as mesmas condições de acesso ao conhecimento propagado nas escolas. Essa escola que, embasada ainda nos dias de hoje à concepção empirista de ensino, os veem como tabulas rasas, desconsiderando 
todo o conhecimento de mundo que trazem para dentro dela. A esses alunos não sobra mais nada senão ocupar seu lugar no banco dos réus pela culpabilização dos resultados de sua escola.

Em um trecho das entrevistas, os professores e a coordenadora foram questionados sobre a avaliação SARESP e os números de DI que a escola possuía, o intuito de tal questionamento era estabelecer alguma relação com os resultados da escola, o número de DI e o fracasso escolar propagado por emio dos índices do IDESP. Traremos algumas respostas problematizadas para o contexto do artigo.

O professor de matemática Well, retrata um dos grandes problemas da adaptação curricular, pois as aulas diferenciadas para os alunos tidos como DI exigem mais atenção e tempo, mas a maioria dos professores não dispõe desse tempo, uma vez que a grande maioria possui cargas horárias integrais para complementar a renda. A justificativa do professor nos empurra para outras questões relacionadas à condição da categoria que começa pela desvalorização da carreira do professor ${ }^{5}$, na qual os baixos salários fazem com que a profissão de professor seja apenas um "bico" ${ }^{6}$, uma vez que muitos precisam complementar a renda com outros trabalhos ou com a duplicação da carga horária. Nesse emaranhado de problemas, o ambiente que deveria ser de aprendizagem e reflexão acaba sendo "sucateado" e os professores acabam se referindo como reprodutores de um saber pronto, sem autonomia.

E: E os alunos que são diagnosticados como deficientes intelectuais? Prof. Well: Isso é um grande desafio Fala-se em aulas diferenciadas. Mas e o tempo?

Não me vejo gabaritado a ministrar aula para uma criança que não sabe ler. Afinal o grande problema de aprendizado matemático é a interpretação de texto. Eu digo pra você, assim como você também deve pensar a mesma coisa, não tem o que fazer, tem que trabalhar com quem tem possibilidade de aprender, infelizmente não dá pra fazer muita coisa.

E: Na realização da prova do SARESP, você acha que o alto número de alunos com diagnósticos de DI implica nos resultados dessa avaliação?

\footnotetext{
${ }^{5}$ Há autores que ampliam a questão das condições de trabalho, como Aparecida Neri de Souza, dentre outros.

${ }^{6}$ Haguette (1992) desenvolve esse tema.
} 
Prof. Well: Em muitos ATPCs questionamos diversos gestores de variados escalões sobre o assunto, cujas respostas não passam de especulações. Entra ou não entra, a velha história e ninguém sabe nada. A grande verdade é que a inclusão é importante, mas tem seus revezes, eles não preparam os professores e aí a gente se sente assim, incapaz (EN - Well).

Fundamentalmente, a adaptação curricular é o grande desafio dos professores, mas eles concordam quanto à necessidade de realizá-la, mas novamente vamos de encontro com as questões que atravessam a sala de aula como o tempo de preparação e reflexão sobre as aulas que o professor, na maioria das vezes, não dispõe devido a uma série de fatores relacionados à condição de trabalho em que ele atua. Conforme a Professora Coordenadora, a adaptação curricular é um passo muito importante para o aluno, senão continuará excluído dentro da sala de aula.

\section{E: Como você compreende o trabalho dos professores durante o ano letivo principalmente em relação aos alunos que são diagnosticados como deficientes intelectuais?}

PC Mari: $O$ aluno que é diagnosticado como DI, ele precisa participar de um acompanhamento na sala de recurso, porém a responsabilidade maior do DI é do professor da sala regular, ele precisa fazer as adaptações necessárias pra trabalhar com eles (EN - Mari).

Interessante pensar o que significa essa adaptação curricular; meramente uma necessidade de nivelar os sujeitos. Nivelar por um padrão construído externamente à escola e um padrão que diz que todos devem estar num mesmo nível, a despeito de todas as diferenças que nos marcam.

Quanto à professora de sala de recurso, antes de transcrever sua resposta em relação à avaliação do aluno diagnosticado com DI, utilizo outros trechos de sua entrevista para compreender melhor o perfil dos alunos que frequentam a sala de recurso e algumas considerações sobre o motivo de eles estarem lá. Primeiramente, inicio essa análise com as impressões da professora da sala de recurso ao iniciar seu trabalho nessa instituição em 2013.

Então aqui tem vários níveis né? Deficiente intelectual, físico mesmo é só a G. que tem um comprometimento motor devido à sequela que ela teve, aquela paralisia de um lado só do cérebro que acarretou os movimentos e eu tive que desenvolver um trabalho de psicomotor com ela porque ela não participa de atividade física pelo medo de cair. 
Mas é mais deficiência intelectual mesmo, tem o leve que é o primeiro grupo que é mais a parte de estruturar mesmo, mas agora tem aquele outro grupo que é assim, além de comportamento que é o que mais pega, tipo a S., não dá pra começar a trabalhar a parte pedagógica com ela ainda, agora eu tô começando, mas era uma aluna que chegava, não olhava nem pra você, como é que você vai entrar trabaIhando. Então assim, é todo um trabalho com ela de socialização primeiro. [...]. Então o que eu encontrei aqui, é a DI mesmo de vários níveis e trabalhar a socialização porque isso eles não têm também.

Também convém destacar da entrevista o modo como eles são encaminhados à sala de recurso, uma vez que tal processo pode configurar um equívoco e um estigma irremediável, já que o aluno que é considerado DI levará esta marca para toda a sua vida. Sentindo-se impotente, limitado, suas chances de sucesso escolar estarão escassas, terá fracassado pela simples, mas cruel, internalização do discurso da incompetência que às vezes começa na própria casa, mas a escola o propaga pela boca de seus professores.

Sobre o estigma, Goffman (2004) o define como um atributo que um indivíduo possui e que o torna diferente dos outros, diminuindo-o perante a eles, resultando em sua rejeição e possivelmente exclusão por parte das outras pessoas. Para o autor, há uma relação direta entre o estigma e o sentimento de descrédito que o acompanha, no qual o indivíduo só é olhado pelo ângulo de seu 'defeito' e qualquer erro que ele cometa será interpretado como "uma expressão direta de seu atributo diferencial estigmatizado" (GOFFMAN, 2004, p. 24).

\section{E: Como é feito o encaminhamento do aluno pra sala de recurso?}

Prof. Rita: É feito por vocês (professores), vocês são os principais, o ponto $x$ da questão, por isso que eu sempre falo, nosso tempo é curto pra trabalhar com vocês né? Eu gostaria muito de ter um horário, tanto que nossas fichas têm o material preparado para o aluno junto com o professor, então o trabalho tá muito ligado só que o tempo de conciliar, uma aula reduzida ainda, ou eu fico com o aluno ou fico com o professor. Então assim, às vezes a gente troca alguma aula e até deixa de fazer alguma coisa.

[...]

Então voltando, vocês são o ponto $x$, isso porque vocês que vão em sala de aula detectar a dificuldade daquele aluno, você na sua área ou até mesmo em, de repente você vê que ele não realiza cálculo. Então vocês 
vão contar como vocês sempre fazem. Vocês têm o Anexo $l^{7}$ e vocês sempre vão preencher, às vezes coletivamente, então vocês vão fazer um relatório, não é nem um relatório, vão colocar o ponto crítico da criança lá: não presta atenção, fica afastado do grupo, não interage ou o aluno é agressivo, tanto com o professor às vezes com o aluno. Essa agressividade tanto pode ser verbal ou até mesmo física, eu já peguei aluno aí que chuta a porta que chuta a janela, tive relatórios assim.

E: Então a gente faz essa indicação, eles vêm até você e daí você faz? Prof. Rita: Ele vem aqui, eu vou ler o que vocês mandaram, eu vou aplicar uma atividade em cima daquilo lá, a avaliação pedagógica não fica só num dia, não é igual a quando você faz um exame médico lá e fala que você tem tal coisa, não ele vem e normalmente eu levo duas semanas, vem, faz, aplica raciocínio lógico, desenvolvimento da escrita, parte social, depois a gente chama os pais, faz Anamnese (anexo 5) que é o histórico da criança desde que nasceu, o atual, com quem ele vive, a maneira que ele vive, daí faz um monte de perguntinhas. Aí você faz uma soma do que o professor falou via o anexo I, o que o pai ou a mãe ou o responsável, que às vezes mora com a vó, faz uma soma aí vai analisar se tem necessidade de inserir esse aluno na sala de recurso ou de repente é só uma fase momentânea que a criança se encontra, alguma coisa emocional, aí você faz o relatório, se for pra sala de recurso já faz a inclusão, se não, a gente faz a devolutiva que a gente fala e fala o que deve ser trabalhado, alguma coisa nesse sentido. $O$ aluno apresenta dificuldades, mas não como DI, ele pode ser apoiado pelo professor PA (professor de apoio) ou um trabalho com mais atenção do professor de sala de aula.

Nesses dois recortes da fala de Rita fica clara a responsabilidade do professor da sala regular para com os alunos que frequentam a sala de recurso como DI, pois começa pelo diagnóstico inicial que é feito por ele, muitas vezes pesando a questão da disciplina para seu diagnóstico. Além disso, há também a falta de preparação dos professores para com os alunos que apresentam dificuldades maiores para a aprendizagem. Essa situação é justificável pela análise do contexto em que os alunos estão inseridos; situações que vão desde a falta de materiais às salas superlotadas impedindo o professor de trabalhar de forma diversificada para atender a todos de maneira satisfatória.

Dos encaminhamentos feitos pelos próprios professores da sala de aula, o risco de colocar alunos que apresentam defasagem de aprendizagem como deficientes intelectuais é

\footnotetext{
${ }^{7}$ Nome dado pela professora da sala de recurso para este documento, pois neste trabalho ele se encontra no anexo 6.
} 
muito grande. Primeiro porque tal relatório está carregado de juízos de valor, como o comportamento do aluno em sala de aula, segundo porque não somos os especialistas nessa área, o que gera uma tremenda confusão quanto à classificação do aluno, configurando o que chamarei aqui de Pseudo DI.

Entretanto, segundo a Nota de Orientação Técnica no 04/2014 SECADI/MEC, não é necessária a apresentação de documentos clínicos comprobatórios (laudo médico/ diagnóstico clínico) para inserção da matrícula do aluno com deficiência, transtorno global do desenvolvimento e de altas habilidades/ superdotação no Censo Escolar 2014. Segundo a nota técnica, o Atendimento Educacional Especializado (AEE) é caracterizado por atendimento pedagógico e não clínico, mas não impede o professor de AEE de se articular com profissionais da área da saúde, tornando o laudo médico um documento anexo ao Plano de AEE, porém este não passa a ser obrigatório, mas complementar.

Em outro trecho da entrevista com a professora da sala de recurso, ela justifica a entrada de muitos alunos para o AEE e algumas das mudanças feitas por ela quando entrou para a escola.

E: Mas aí você tinha falado que fomos nós mesmos que indicamos eles na sala de recurso, eu não sei porque eu estou aqui há 4 anos e quando eu cheguei já tinham vários alunos que tinham o nome listado como DI.

Rita: Que não eram!

Então é uma coisa que eu consegui assim, graças a Deus!

\section{E: Nos anos anteriores, quanto aluno tinha hein!!!}

Rita: Sabe o que é, eu acho que, eu acho não, eu tenho certeza, tem que ser justo, falando como professora e como mãe, ninguém quer uma criança como DI numa sala de recurso, é que nem às vezes assim, falaram que pode fechar sala, eu falei pro PCNP, que eu perco a minha sala, mas eu não fico com aluno que não é DI. Então, assim, o meu objetivo qual foi o ano passado, eu fui fazendo avaliação, eu fui fazendo tudo que o aluno desenvolvia, eu já excluí três, desde o ano passado porque eu não fico, aí mais vai correr o risco de perder a sala, eles estavam preocupados, assim essa preocupação não tenho porque eu perco aqui, eu ganho lá. Eu não deixo aluno na minha mão, assim, existe, eu fico de olho no D. e no L.F. que ainda, depois do trabalho desse ano, pode ser que o ano que vem eles nem entrem na lista, porque ainda eles precisam de algumas habilidades que ainda não têm. O aluno na sala de recurso, lendo, escrevendo, tendo raciocínio lógico, assim, rápido, ele próprio chega pra você e fala "eu não sou DI, eu só preciso de reforço". Então, eu não acho justo, ainda o objetivo do meu 
trabalho, a sala de recurso, ela tem que ser trabalhada em nível de alfabetização, ela tem que ser pra aquele aluno que não tem o conceito de leitura e escrita. Aqui ainda tem disso, por ser ensino fundamental, ainda tem algumas dificuldades que até a gente releva, mas não dá. Então, o ano passado tinha 2 alunos aqui, eu falei, esses alunos não são DI, daí não podia tirar ainda porque tava na lista, aí foi indo, eu fui comprovando por relatórios e no final do ano eu exclui. Então eu faço a devolutiva.

Então pense bem, porque eu citei professora e mãe, porque professor tem que ter a noção, o bom senso de pensar porque que esse aluno tá na minha sala, agora como mãe, ninguém quer uma criança, se ela for vamos aceitar do jeito que ela é e vamos trabalhar e buscar o que é melhor pra ela só que ela não é gente. Vai deixar na sala pra que, pra fazer volume, então assim, eu exclui o L., a L. A., porque a menina é comportamento, então encaminhei pra psicóloga, agora o S. foi uma coisa assim, ele veio pra mim da Escola J. F., o menino lê, o menino escreve, você dá aula pra ele, ele tinha dificuldade em divisão que até a gente tem, então fazer o menino levantar cedo, $7 \mathrm{~h}$ da manhã, todo dia, pra vir escutar aqui o que é numerais de 1 a 9, gente isso aí é criar um trauma, é a mesma coisa, você não tá com dor de cabeça e ter que tomar um remédio pra dor de cabeça. Eu falo e repito, eu não deixo aluno que não é, vamos dizer assim, eu tenho que ficar com 5 senão eu vou perder a sala, eu não tenho esse medo!

Eu mando os relatórios, o que vocês mandaram, o desenvolvimento na sala, a dificuldade não apresentada, nada que faça com que ele necessite do atendimento especializado e depois o relatório final.

No relatório a gente deixa claro que a gente não tá falando em nenhuma área clínica, pode apresentar no decorrer dos anos alguma dificuldade, é muito difícil que ele volte pra sala, mas no caso de quem é esforçado, não apresenta sérias dificuldades, não vai ter necessidade de voltar.

\section{E: Você acha que há uma confusão de DI com defasagem de aprendi- zagem?}

Rita: Tem... porque olha, alguns professores já comentam comigo, eu acho que o dele é dificuldade, às vezes ficou aquela "vaguinha" lá no começo e vai indo, vai desenvolvendo, a mãe não presta atenção em como o filho desenvolve, o tempo passa e ficou lá na frente aquela coisa sem aprender, então existe o professor que chega, "ah tem o fulano lá, mas acho que ele não é DI, é uma dificuldade de aprendizagem, mas a maioria fala que é DI mesmo. Eu acho que tá meio confuso ainda e como aqui tem a sala de recurso já vai direto pro DI, como tem só essa salinha aqui tudo que vem de um pouquinho de dificuldade já querem dar um jeitinho.

[...]

Eles confundem muito e vem parar aqui, mas na minha mão não fica muito porque eu não seguro muito! 
O discurso da professora é bem contundente sobre a produção de casos de DI no interior da escola. Alunos que têm problema de relações e comportamento em sala e não têm dificuldade de aprendizagem significativa são encaminhados e números produzidos. Eles são números criados ora para manter a sala de recursos, ora, talvez, para impedir que o índice da avaliação esteja muito abaixo do esperado. Interessante o fato de a professora fazer essa denúncia e, a partir de seu lugar de micro poder, devolver esses alunos para suas turmas, negando o diagnóstico inicialmente construído.

Quanto ao processo de avaliação da aprendizagem do aluno diagnosticado como DI, destaco três momentos: ele realiza as avaliações propostas pelo professor da sala regular juntamente com os demais alunos, as avaliações diárias com o professor do recurso chamado de anexo II e a avaliação externa como o SARESP dependendo da série em que eles estiverem.

\section{E: Você faz avaliações com eles? Como você avalia a aprendizagem} deles?

Rita: Avaliação, prova você tá falando?

Então, prova... não, o avanço dele é diário, o que eu faço são os relatórios finais que são o anexo III. Então já falamos do Anexo I que é o de vocês, do II que é o diário e o III que encerra o bimestre. ${ }^{8}$ Aí sim, você vai falar por meio, você vai descrever esse aluno, se ele teve rendimento, se ele ainda necessita atingir aquele objetivo que você traçou pra ele ou se dá pra acrescentar mais alguns, que nem tem aluno que entra até a parte de higiene, não tem, não sabe fazer, então ele teve avanço nessa parte, aí você já deixa de lado, você vai só dando as orientações, mas não vai ficar focando naquele trabalho lá.

E: Então, na sala de aula, os alunos que fazem recurso fazem as avaliações normais com os outros, mas nas médias já fica estipulado de dar média 5 porque é inclusão.

Rita: Que não é o correto... porque assim, o aluno é avaliado no que ele sabe e no que não sabe e um aluno DI também tem o que ele sabe e o que não sabe, então assim, não tem porque ele ser avaliado diferente, então desde que eu entrei aqui eu não sei se é em todos os lugares, mas conversando com o PCNP, ele falou que não existe esse negócio, porque assim, às vezes ele merecia tirar mais que 5 e às vezes me-

\footnotetext{
${ }^{8}$ Os anexos ao qual a professora se refere são os nomes dados aos documentos, eles podem ser encontrados no trabalho na íntegra de Mestrado, nos Anexos: 6, 7 e 8.
} 
nos que 5, então não é justo, às vezes aquele aluno assim que se esforça, responde oralmente ou fez um trabalho em grupo, contribui, depois ele tira um 5 e se ele merecesse um 8, agora vamos pensar o contrário, aquele aluno que além de não ter um desenvolvimento cognitivo bom, ainda ele junta com a falta de interesse, indisciplina, que tem, porque não é porque é DI que não vai ter, a maioria daqui são de comportamentos terriveis. Então ele juntou tudo que não está de acordo com as regras da escola e aí ele tira um 5 , não é justo com aquele que tentou, mas infelizmente é o meio aqui.

\section{E: E como é a receptividade deles em relação a essa prova? Não quero fazer, não vou?}

Rita: Não eles vêm, eles entendem de tudo que acontece na escola, se é prova, porque que vai ser. "Ah agora amanhã eu vou ter prova com a Danielle lá, ah mais é fácil, vai cair não sei o que...". Eles entendem de tudo, então assim, eles são bem situados, quanto a isso eles não têm diferença dos demais, mas o SARESP eles ficaram preocupados, ah tem quantas perguntas, não sei o que, em momento nenhum eles falam também, não sei ler, como é que vou fazer, eles são tão acostumados com isso que eles fazem, não sei que coragem que dá, mas eles fazem.

E: Você já ouviu falar de um discurso (não oficial) de que o aluno que está computado na PRODESP como aluno com DI não contabiliza no resultado dessa prova?

Rita: Eu ouvi falar, só que eu já ouvi falar que contabiliza sim, por isso que a "Mari" (coordenadora) falou que era bom que eu entrasse (no dia do SARESP) para auxiliar pelo menos na leitura na hora ali deles interpretar, só que como o ano passado teve bastante DI, só na sala do $7{ }^{\circ}$ ano eram 8 , então, quer dizer que conta?

E: Quando a gente recebe o relatório do SARESP, vem lá quantos fizeram a prova e quantos estão abaixo do básico, teve um ano que foi possível identificar que justamente os que estavam abaixo do básico, tinha só uma oitava série, então era mais fácil de ver né, eram os oito alunos $\mathrm{DI}$, digo, podiam ser, o número bate.

Rita: Então, mas que nem o ano passado, na hora de fazer essa correção, como que eles vão tirar esses $D I$, eu acredito que, não é nada oficial, como você falou, mas acredito que conta. E aqui não são poucos, por isso que teria que encontrar uma maneira de estar trabalhando com eles, mas chega na hora, se o aluno não adquiriu ainda a leitura e a escrita, porque eu falo leitura e escrita porque sem elas eles não conseguem interpretar nada, não conseguem ler um enunciado ou a comanda da atividade, não tem como.

\section{$\mathrm{E}: \mathrm{E}$ isso influenciaria no resultado?}

Rita: Com certeza né (risos), porque não são poucos, eu tenho 10, a 
outra professora, do período da tarde são mais 10, então são 20 alunos. Então com certeza interfere né, no resultado, que não foi bom né? (EN - Rita)

Das falas sobre preocupação dos professores com as avaliações externas e das alternativas propostas pelos professores de como ajudá-los com a leitura no momento do SARESP, o que fica é a busca de uma qualidade de ensino a todo custo, mas que acaba criando novas formas de exclusão dentro da escola. E essa busca a todo custo significa ignorar sujeitos presentes nas crianças ditas com Deficiência Intelectual.

Ao analisar amplamente a situação, os sujeitos são cristalizados, são considerados como um objeto de manipulação para a conquista de índices que proporcionarão bônus, melhores colocações, menor desprestígio no interior do sistema. $\mathrm{O}$ grande sacrificado é o aluno. É a lógica da subordinação e exclusão em jogo, que impera sobre a forma de organização escolar.

Segundo Freitas (2002), a batalha pela equidade que tanto desejamos no sistema educacional não pode ser realizada sem o apoio de amplos movimentos sociais emancipatórios que denunciem a base das explorações vigentes. Trata-se de compreendermos antes de que educação estamos falando e em qual sociedade, pois segundo esse mesmo autor, há décadas os educadores lutam por acesso a uma educação de qualidade, a questão do acesso foi facilmente ajeitada sob o viés de obrigatoriedade do ensino para todas as crianças. Entretanto, a qualidade deixou a desejar, talvez por inadequação da classe popular aos costumes de uma cultura elitista propagada na escola.

Para Freitas (2002), as dificuldades para a melhoria da qualidade das escolas advêm do próprio modelo de escola e das possibilidades de aumentar esta qualidade por adição de controle sobre a escola (especialistas supervisionando os professores, controle do currículo, avaliação interna e externa). Em uma sociedade capitalista esse é o modo mais hábil de se enxergar uma escola de qualidade, exercendo controle sobre ela, assim como nas empresas.

Para compreender essa lógica, o autor utiliza o termo "internalização dos custos" em que o sistema escolar toma consciência de que repetência e evasão geram despesas para os cofres públicos, então o que é proposto como uma política de corte de gastos são outras medidas paliativas para manter os alunos na escola. Nessas medidas podem ser incluídas as aulas de reforço e as salas de $A E E$, uma vez que não resolvem todo o problema, mas mantêm os alunos na escola garantindo a permanência. 
A crítica não é sobre as salas de reforço ou sobre o atendimento especializado, mas sobre a "exclusão internalizada", termo cunhado pelo autor para se referir ao aluno que permanece na escola mesmo sem aprender e que se ganha clareza e controle sobre seus custos econômicos (com programas de Correção de Fluxo, Classes de Aceleração, Classes de Reforço etc.) (FREITAS, 2002, p. 306). Sob o discurso de inclusão todos têm seus lugares na escola, seja na sala regular ou de recurso, colocando a todos, professores e alunos na conformação de seus lugares.

Exceto em tempos de avaliação externa, pois elas chegam para verificar a qualidade da escola, nesse momento é preciso que todos ocupem seus lugares. Os alunos que apresentam algum déficit serão os únicos responsáveis por não aprender, os professores que não ofereceram outro tipo de atendimento aos alunos com dificuldades também serão cobrados por isto. Essas ações comprovam a tese de Freitas de que "quanto mais se falou em responsabilizar a escola pelo ensino para todos, mais desresponsabilizou a ação da escola pela aprendizagem das camadas populares" (FREITAS, 2002, p. 317).

\section{Algumas das táticas produzidas: não precisa mais pintar, agora pode ser $\mathrm{X}$}

O conceito de tática desenvolvido por Certeau (1998) é nada mais que ações calculadas com o propósito de "jogar com o terreno que lhe é imposto" (p. 100). São momentos oportunos para desenvolver novas ações, sem, contudo, deixar de cumprir as que the foram exigidas. Nesse âmbito, destaco algumas ações realizadas pelos gestores e professores com intuito de "melhorar" o resultado da escola no cálculo do IDESP. Tais ações vão desde o treino de atividades que se assimilam às questões apresentadas no SARESP ao treino do gabarito para tal avaliação. Também a própria Diretoria de Ensino faz uso de avaliações com estrutura semelhante à do SARESP e que é aplicada em todas as escolas da Diretoria. Essas avaliações ocorrem bimestralmente e por meio delas é possível, além de treinar, diagnosticar o andamento de cada uma de suas escolas.

A avaliação adotada pela Diretoria de Ensino de nome "Avaliação Diagnóstica" é bem vista pelos professores principalmente porque, segundo eles, seus resultados são palpáveis, podendo assim visualizar o desempenho individual de cada aluno e fazer as intervenções necessárias para que, ao final do ano, os discentes possam ter melhores resultados na avaliação externa SARESP. 


\section{E: Há alguma mudança nas práticas escolares e avaliativas em função do SARESP? Alguma que tenha te chamado a atenção?}

Prof. Well: Sim. As avaliações diagnósticas voltadas para o SARESP sempre ajudam nas intervenções e melhorias. Principalmente porque essas sim a gente vê ali o que o aluno errou o que ele acertou e o que precisa trabalhar mais. Se o SARESP fosse assim, ia nos ajudar bastante!

E: Qual o grau de receptividade dos alunos em relação a essa avaliação em seu ponto de vista?

Prof. Well: Adolescente não gosta de imposições. As eleições estão chegando, quantas vezes não ouvimos reclamações sobre a obrigatoriedade do voto. Essa é a questão, deveriam avaliar somente os alunos que querem ser avaliados, os demais devem ser colocados sim na estatística. É preciso pensar nisto (EN - Well).

A fala do professor nos remete a alguns pontos dessa avaliação externa que merecem ser analisados com mais calma, primeiramente porque ao adentrarmos ao campo dos sentidos produzidos pelos sujeitos, compreende-se que o sentido da avaliação para esse professor está na possibilidade de verificação da aprendizagem. Esse é um conceito de avaliação ressaltada por Luckesi (2008) a que chamou de avaliação formativa objetivando, assim, o desenvolvimento de aprendizagens. Essa concepção corrobora com a fala do professor quanto à necessidade de trabalharmos no campo do diagnóstico, da verificação do que o aluno ainda não sabe para as possíveis intervenções.

Nesse ponto, a avaliação proposta pela Diretoria de Ensino e exemplificada pelo professor, reflete a dual relação entre o processo de ensino e aprendizagem, pois ela dá condição para que o professor, em sua prática, reflita seu processo de ensino, bem como a possibilidade de diversificação de suas metodologias e, ao mesmo tempo, tendo condição de refletir a aprendizagem de seus alunos. O questionamento do professor entrevistado está na ideia de imposição que a avaliação externa apresenta, justamente por acreditar que o aluno não tem maturidade para realizá-la com seriedade, mas independente disso, seu resultado impacta na realidade da instituição.

Ainda no tocante a essa ideia, o professor compara essa ação com a da obrigatoriedade do voto, alegando que quando não se vê sentido no que se está fazendo, o "fazer" torna-se apenas uma burocracia a ser cumprida afastando o real significado da avaliação. 
Quando o sentido se perde, entram as táticas que, a certo ponto, mascaram a aprendizagem em detrimento de um resultado, como se vê nessa passagem do Registro Reflexivo da escola, escrito pelo professor de arte "Luiz".

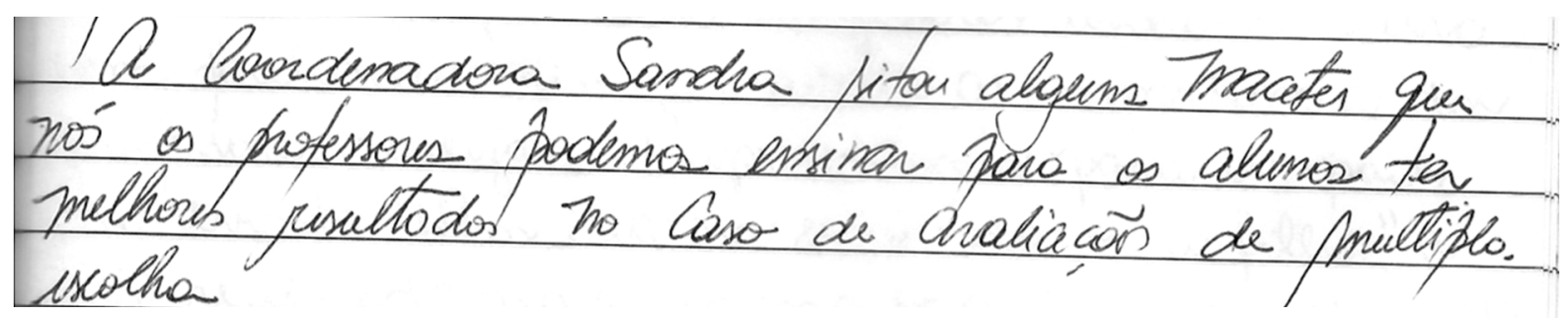

Figura 1 - Registro reflexivo Prof. Luiz

O uso de macetes é muito comum em cursinhos pré-vestibulares e estes estão mais relacionados a decorar conteúdos do que se apropriar deles, porém isto não significa que os professores não estejam ensinando, apenas preparando os alunos para uma avaliação específica que altera a rotina da escola.

Quanto aos alunos que frequentam a sala de recurso, a solução encontrada pelo grupo foi a de treinos no gabarito, como ressalta a professora de atendimento educacional especializado:

\section{E: Vai chegar o fim do ano e eles vão fazer o SARESP, e nesse dia você pode ajudá-los?}

Prof. Rita: Não pode, o ano passado o que eu consegui com eles assim, foi bastante treino no gabarito, eu imprimi porque às vezes assim eles se perdem na hora de passar a limpo, então às vezes, tá certo e ainda passa errado, então eu fiz esse treino com eles, a maioria até que foi, depois falaram que não precisava mais pintar, podia ser $x$, só que assim, o ano passado eu estava entrando na sala aí a PCNP perguntou onde que eu tava indo, porque até então o único que poderia entrar na sala seria o professor de recurso para acompanhar aquele aluno com dificuldade. Só que a dificuldade era só se fosse física, mas na parte da DI eu fui barrada, eles fizeram a prova eu nem sei como (EN - Rita).

Como descreve Certeau (1998), sobre o uso das táticas, estas dependem do tempo, vigiando para o "captar no voo" possibilidades de ganho e é assim que, no andamento das aulas, a professora da sala de recurso descobre a dificuldade que os seus alunos têm em preencher gabaritos, então utiliza como tática seu preenchimento. Porém, como ressalta Certeau (1998, p. 47) sobre as táticas, "o que se ganha não o guarda, tem constantemente que jogar com os acontecimentos para transformá-los em 'ocasiões'”. Foi nesse ponto que a tática falhou, pois mudou 
a forma de preenchimento do gabarito, o que pode ter causado uma confusão na cabeça dos alunos que estavam condicionados a pintar a bolinha do gabarito.

As maneiras de fazer dos profissionais envolvidos com as crianças na escola merecem respeito, pois são formas de resistir num sistema que aniquila os sujeitos, mas também se mostram contraditórias. Em nome de melhoria dos índices, constroem maneiras de fazer, táticas que, muitas vezes, colaboram para ocultar os sujeitos que não aprendem e acabam por não denunciar explicitamente os processos de exclusão a que estão submetidas as crianças no interior da escola. À medida que as crianças rotuladas de Deficientes Intelectuais são treinadas a qualquer custo ou são ignoradas na contagem dos dados, elas estão também sendo ignoradas pelo poder público. Mas quem colabora com essa produção de ignorância? Os próprios profissionais do interior da escola.

\section{Últimas palavras}

Ao construir as sínteses, sempre provisórias, deste texto, retomamos o objetivo inicial: a compreensão de sentidos e táticas dos professores para a relação avaliação externa DI em uma escola prioritária. E nossa primeira reflexão está no campo desse tipo de escola. Se escolas prioritárias são aquelas que não conseguiram atingir uma meta prevista na avaliação externa SARESP quanto ao aprendizado de seus alunos, elas representam aquilo que a própria SEE chamou de "escolas com vulnerabilidade educacional", sendo, para a secretaria, "carente de aprendizado". Se carente de aprendizado, cabe aos professores e gestores, diante do discurso oficial, ser responsabilizados pelos resultados. E esse é o mote das ações explicitadas nos sentidos produzidos. Quase todos os sentidos vão em direção a compreender primeiro que são necessárias adaptações curriculares para que essa carência seja reparada. E segundo, o sentido que, para que essa adaptação ocorra e, dentro da lógica, é necessária outra condição de trabalho.

Diante do quadro que apresentamos sobre DI e os discursos dos professores, pouco pudemos encontrar de questionamento sobre a produção do DI na escola, com exceção da professora de sala de recursos que denuncia como ele é produzido, inclusive como resultado de táticas para que o índice seja atingido. Nesse sentido, percebemos que os profissionais aprenderam a trabalhar no campo das "táticas" (CERTEAU, 1998) e sua primeira ação nesse contexto é atribuir a responsabilização pelo aprendizado ao próprio aluno, invocando uma causa natural como a Deficiência Intelectual. Outra tática é a criação de espaços de treino. Lembremos que 
treino não é educação. O resultado de treino não é aprendizagem.

Entretanto, o jogo das táticas não produz um quadro seguro, justamente porque elas devem ser constantemente modificadas porque só funcionam em um determinado tempo. Além do mais, ao justificar o fracasso no aluno que é DI, corroboram com a ideia que ele faz parte de um grupo que não precisa ser avaliado, não há responsabilidade nem da escola, nem da rede oficial para com eles. São, por fim, excluídos.

Outro sentido produzido pelos professores em relação ao SARESP e à Escola Prioritária é o desejo de tornar esta avaliação mais democrática ao ponto que os professores tenham em mãos os resultados "reais" de seus alunos para que assim possam intervir de maneira eficaz no aprendizado de seus alunos. Essa fala demonstra a extrema falta de autonomia dos professores, uma vez que não é preciso ter o resultado "real" dos alunos a partir de uma avaliação externa para então intervir no aprendizado deles. Tal desejo caracteriza o reconhecimento de que a avaliação pode e deve ser um instrumento formativo capaz de trazer à tona a práxis educativa, porém, esta política de intervenção ocasionada pelo resultado do SARESP, a de Escola Prioritária, só evidencia aquilo que esta avaliação traz de mais perverso: a individualização do fracasso escolar via professor e aluno.

\section{Referências}

BOURDIEU, P.; CHAMPAGNE, P. Os excluídos do interior. In: BOURDIEU, P. Escritos de educação. 3. ed. Petrópolis: Vozes, 2001. p. 39-64.

CERTEAU, M. A Invenção do Cotidiano: artes de fazer. 3. ed. Petrópolis: Vozes, 1998.

FREITAS, L. C. A internalização da exclusão. Ed. e Sociedade, v. 23, n. 80, p. 299-325, set. 2002. Disponível em: http://www.cedes.unicamp.br. Acesso em: 16 jun. 2014.

GÓES, M. C. R. Desafio da inclusão de alunos especiais: a escolarização do aprendiz e sua constituição como pessoa. In: GÓES, M. C. R.; LAPLANE, A. L. F. Políticas e práticas de educação inclusiva. Campinas: Autores Associados, 2007. p. 81-98.

GOFFMAN, E. Estigma: notas sobre a manipulação da identidade deteriorada. Tradução Mathias Lambert. Data da Digitalização: 2004. Data Publicação Original: 1891. Disponível em: <https://we.riseup.net/assets/212390/versions/1/Erving\%20Goffman\%20ESTIGMA.pdf>.

Acesso em: 13 mai. 2013.

GONÇALVES, R. A.; MACHADO, C. Violência e vítimas de crimes. Portugal: Quarteto Editora, 2002. 
LUCKESI, C. C. Avaliação da aprendizagem escolar: estudos e proposições. 19 ed. São Paulo: Cortez, 2008.

MOYSÉS, M. A. A. A institucionalização invisível: crianças que não aprendem na escola. Campinas: Mercado de Letras, 2001.

SÃO PAULO (Estado). Secretaria da Educação. Núcleo de Apoio Pedagógico Especializado - CAPE. Deficiência Intelectual: Realidade e ação. Organização, Maria Amélia Almeida - São Paulo: SEE, 2012.

VYGOTSKY, L. S. Pensamento e linguagem. 2002. Disponível em: http://www.jahr.org. Acesso em: 05 out. de 2014. 